\title{
Ebstein Anomaly
}

National Cancer Institute

\section{Source}

National Cancer Institute. Ebstein Anomaly. NCI Thesaurus. Code C84681.

A rare congenital heart malformation characterized by apical displacement of the opening of the tricuspid valve. The defect involves both the right ventricle and the tricuspid valve, and can lead to cardiomyopathy and tachyarrhythmias. 